\title{
Fontes literárias da cultura brasileira para a história dos saberes psicológicos
}

\author{
Literary Sources of Brazilian Culture for the History of Psychological \\ Knowledge
}

\author{
Marina Massimi \\ mmassimi3@yahoo.com \\ Professora titular \\ Universidade de São Paulo - campus de Ribeirão Preto \\ Rua Américo Brasiliense, 1340/ 111 \\ 14015-050 - Ribeirão Preto - SP \\ Brasil
}

\section{Resumo}

Neste artigo é discutida a utilização das fontes literárias no âmbito da história dos saberes psicológicos. Em primeiro lugar, apresenta-se a contribuição de Dilthey e de Huizinga na discussão das interfaces entre história, psicologia e literatura. Em segundo lugar, apresenta-se um exemplo de análise de fonte literária no âmbito da história dos saberes psicológicos: o estudo da novela alegórica do jesuíta Alexandre de Gusmão, História do Predestinado Peregrino e de seu irmão Precito (1682). Aponta-se que a fonte literária pode ser enfocada da perspectiva da história dos saberes psicológicos, seja por ser transmissora de conceitos e práticas psicológicos, seja pela ação exercida no dinamismo psíquico dos destinatários por meio de sua construção retórica.

\section{Palavras-chave}

História cultural; Retórica; Historiografia jesuítica.

\begin{abstract}
This article discusses the use of literary sources in the context of the history of psychological knowledge. Firstly, it presents the contribution of Dilthey and Huizinga in the discussion of the interfaces between history, psychology and literature. Secondly, it presents an example of a literary source analysis in the context of the history of psychological knowledge: the study of the allegorical novel written by the Jesuit Alexandre de Gusmão, História do Predestinado Peregrino e de seu irmão Precito ("History of the Predestined Pilgrim and his Reprobate Brother") (1682). It points out that the literary source can be approached from the perspective of the history of psychological knowledge both on account of its ability to transmit psychological concepts and practices and to exert effects on the psychic dynamism of the recipients by means of rhetorical construction.
\end{abstract}

Keywords

Cultural history; Rhetoric; Jesuit historiography.

Recebido em: 24/4/2014

Aprovado em: 16/6/2014 
A utilização de fontes literárias no âmbito da investigação histórica é um caminho que tem sido apontado e recomendado pelos filósofos e percorrido por vários historiadores contemporâneos. As fontes literárias documentam a historicidade da experiência humana na medida em que, entre outras funções, desempenham aquela de elaborar e transmitir conhecimentos utilizando-se dos procedimentos textuais que Ihes são próprios. Desse modo, nelas podem-se encontrar saberes que dizem respeito à experiência humana em suas dimensões temporais. Assim acontece no campo de atuação da história dos saberes psicológicos, parte da história cultural que, inspirada nas perspectivas apontadas por De Certeau (1975/2000) e Chartier (1985/1990), busca reconstruir a gênese e as diferentes significações de conceitos e práticas psicológicos em diferentes contextos espaço-temporais. A partir dessa perspectiva metodológica é que iremos discutir, neste artigo, as interfaces entre história, psicologia e literatura. Apresentaremos a seguir as contribuições de alguns autores que foram pioneiras quanto à abordagem metodológica de análise e interpretação das fontes focando as importantes relações entre os domínios da história, da psicologia e da literatura. E, num segundo momento, colocaremos um exemplo concreto de utilização de uma fonte literária produzida no âmbito da cultura brasileira colonial da perspectiva da história dos saberes psicológicos.

\section{Interfaces possíveis entre história, psicologia e literatura no horizonte da epistemologia não reducionista de Wilhelm Dilthey}

Pioneiro na tematização da relação entre história, psicologia e literatura é W. Dilthey (1833-1911). Este autor, ao romper com a imposição positivista quanto a um método único para o conhecimento dos fenômenos, discute de uma maneira inovadora as relações entre história, literatura e psicologia, tendo em vista a compreensão da experiência em sua complexidade e unidade vital.

Dilthey (2006) distingue entre os domínios das ciências da natureza e os das ciências do espírito, fundamentando-se na consideração da multiplicidade dos sentidos do conceito de experiência. Tal multiplicidade exige modalidades diversas de abordagem; assinala-se assim a necessidade de demarcar as diferenças entre os dois domínios metodológica e conceitualmente. Desse modo, Dilthey afirma que os dois domínios diferem seja quanto ao ideal metodológico, seja quanto ao objeto de investigação, seja quanto ao tipo de teorização possível.

No que diz respeito às ciências do espírito, com elas visa-se à compreensão do processo de individuação do ser humano do ponto de vista histórico-social; elas têm por objeto os fatos assim como se apresentam no interior, ou seja, como uma conexão vivente, de modo que, se nas ciências da natureza se alcança a explicação dos fenômenos, pelas ciências do espírito se compreende a vida interior. As ciências do espírito investigam a realidade histórico-social, sendo elas: a história, a economia, o direito, a ciência do Estado, a teologia, a literatura, a arte, a filosofia, a psicologia. Para referir-se à experiência consciente da conexão vital, que é o objeto das ciências do espírito, Dilthey introduz a categoria epistemológica da vivência, em oposição à categoria da representação, de matriz kantiana. 
Com base nesses pressupostos, uma essencial convergência entre história, literatura e psicologia (e as demais ciências do espírito) é preconizada por Dilthey na medida em que esses saberes buscam apreender as vivências do homem real em sua concretude, unidas por "conexões vitais" (DILTHEY 2006, p. 252). Toda conexão vital é significativa: "onde quer que a vida tenha passado e tenha ganho a compreensão, há história. E onde há história, a significação se faz presente em sua multiplicidade" (DILTHEY 2006, p. 253).

No que diz respeito à ciência histórica, Dilthey aprofunda o estudo da natureza das conexões entre os eventos do universo histórico, evidenciando que elas diferem das conexões causais: enquanto estas se referem à existência de causas capazes de produzirem efeitos necessários, "a história não conhece senão as relações próprias ao agir e ao sofrer os efeitos do agir" (DILTHEY 2006, p. 175). Tomando o exemplo do gênero autobiográfico, Dilthey observa que as conexões tematizadas pelos autores desse tipo de narrativas se referem sempre à articulação "entre as partes da vida e a concretização de um valor absoluto" (DILTHEY 2006, p. 177) reconhecida como sentido da vida em sua totalidade. Trata-se de "conexões significativas" (DILTHEY 2006, p. 178).

Entre as ciências do espírito, existem, porém, diferenças de abordagem: por exemplo, a psicologia descreve as funções da vida psíquica, ao passo de que a antropologia descreve os conteúdos dos estados psíquicos. Psicologia e antropologia constituem-se em fundamento da história, que é a ciência do espírito mais completa, pois só por ela é possível apreender de modo completo 118 a experiência do homem. De fato, o conhecimento histórico revela o que o homem é ao longo do tempo: na dimensão da temporalidade é "possível ler, em letras maiúsculas, os motivos, os destinos interiores, as relações vitais da natureza humana" (DILTHEY 1880 apud AMARAL 1987, p. 19). Da afirmação de que a consciência humana se desenvolve historicamente decorre que só é possível conhecê-la focando o processo histórico vivo. Assim, segundo Dilthey, na apreensão da subjetividade, é preciso substituir o "cogito" cartesiano e o "eu penso" kantiano pela unidade do "eu penso, eu quero e eu temo" que é dada na nossa consciência e se revela na história.

A análise psicológica é essencial para a compreensão das vivências. A psicologia que tem por objeto as vivências conscientes é do ponto de vista metodológico uma ciência descritiva e analítica. A construção da "psicologia descritiva" encontra-se no texto Ideen Über Eine Beschreibente und Zergliedern de Psychologie (1894). Cabe assinalar que a proposta da psicologia descritiva de Dilthey se origina na negação, por um lado, de uma psicologia fundada na metafísica e, por outro, de uma psicologia fundada no modelo das ciências naturais ("psicologia explicativa", ou psicologia tradicional), resultado da transposição dos métodos científico-naturais para a psicologia.

De modo complementar à psicologia, a literatura, a arte e a poesia são formas de conhecimento importantes do mundo interior do indivíduo: "Quão pobre e mesquinho seria o nosso conhecimento psicológico dos sentimentos sem os grandes poetas que expressam toda a variedade dos sentimentos" (DILTHEY apud AMARAL 1987, p. 36). 
Na perspectiva de Dilthey, portanto, a colaboração entre história, psicologia, literatura e as demais ciências humanas revela-se essencial. Se, por um lado, o universo histórico refere-se a fatos materiais, exteriores, por outro lado, as ciências humanas buscam nesse universo o sentido e a significação que tais elementos materiais assumiram "a partir da atuação do espírito". E é a "compreensão que apreende nesses estados de fato essa significação, esse sentido" (DILTHEY 2010, p. 71). Desse modo, no âmbito da discussão filosófica, Dilthey é pioneiro na tematização da fecundidade heurística proporcionada por abordagens que contemplem os aportes metodológicos históricos, literários e psicológicos.

\section{Interfaces entre história, psicologia e literatura no âmbito da historiografia: a contribuição de Johan Huizinga}

Vários historiadores contemporâneos exploram as ricas interfaces entre história, psicologia e literatura em seu fazer histórico (CHARTIER 1990; CERTEAU 2000; DOSSE 2004). Diversas são as contribuições à construção das interfaces entre análise historiográfica e analise literária das fontes: dentre elas destaca-se o aporte de LaCapra (1985a; 1985b; 1992; 2004). Pinto e Valinhos colocam que LaCapra busca "construir um discurso histórico que não se dissolva na literatura, mas que ao não evitar o contato com ela propicie estudos" mais criativos (PINTO; VALINHOS 2010, p. 5). De fato, segundo as autoras, "a problematização de LaCapra a respeito de noções caras à historiografia, tais como a de documento, de texto, de contexto e linguagem, permite pensar de maneira instigante a relação entre escrita e história" (PINTO; VALINHOS 2010, p. 5). Bariani assim sintetiza a visão desse autor: "O texto - para ele - está em relação com outros textos, difere e aproxima-se destes, está indefectivelmente permeado pelo contexto [...] e não é redutível à condição de 'simples' documento, artefato, registro do passado". Com efeito, "há dimensões no texto [...] insubmissas ao mero inventário". Portanto, exige-se uma "atitude crítica e transformadora" que realize um "diálogo crítico com o texto e os problemas que levanta" (BARIANI 2006, p. 2).

Aqui queremos mencionar a contribuição de um pioneiro: Johan Huizinga (1872-1945). Este autor, ao definir a história como "a forma do espírito (da cultura) em que uma civilização toma conta de seu passado" (HUIZINGA 2013, p. 17, tradução nossa) $)^{1}$ estabelece de modo definitivo o nexo entre a indagação histórica e as culturas na multiplicidade de suas expressões. Com efeito, assim como a história, a literatura é uma forma cultural: a diferença é que a história se interessa pelo passado e exclusivamente por ele; e que ela não possui o elemento lúdico presente na literatura. A história, segundo Huizinga, é a menos independente dentre as demais áreas do saber por ter constante necessidade do auxílio das demais para dar forma aos seus conceitos, para definir suas unidades de medida, para preencher seu pano de fundo. Além do mais, o historiador lida com acontecimentos que são por sua natureza fenômenos não

\footnotetext{
${ }^{1}$ No original: "la forma dello spirito (della cultura) con cui una civilizzazione assume il suo passato".
} 
submetidos a leis deterministas: de fato, os fatores presentes num dado tempo passado permitiriam possibilidades diferentes das que ocorreram efetivamente. Inevitavelmente, portanto, o historiador acaba ordenando os fatos históricos segundo categorias derivadas de sua visão do mundo e formação cultural. Nesse sentido, a representação e a narrativa histórica dependem da civilização e da cultura de pertença do historiador.

O historiador pode reconhecer formas culturais em ato no passado na medida em que ele as compreende em seu presente. Isso não significa que a história se reduza à historia romanceada, na qual é amplificado um fator também presente na narrativa histórica: a imaginação, a fantasia. A história romanceada, segundo Huizinga, diferencia-se do romance histórico, "gênero literário irrepreensível" (HUIZINGA 2013, p. 101, tradução nossa)² que "atinge da história seu material, usa o pano de fundo de um dado passado histórico, mas como puro exercício de belas letras, sem pretensão de ser considerada uma verdade rigorosa". ${ }^{3}$ Por contra, segundo Huizinga, "a história romanceada contemporânea pretende fazer história", mas "esses autores não cuidam da sobriedade da verdade a ser conhecida". Introduzem detalhes fantasiosos de tipo psicológico, com mais cores das que seria permitido usar. Os autores da história romanceada - ainda segundo o autor -, não tendo a humildade de reconhecer a própria ignorância, ignoram "que é mais conveniente renunciar a dizer coisas que não se conhecem" (HUIZINGA 2013, p. 102, tradução nossa). ${ }^{4}$ De modo nenhum, portanto, o "historiador rigoroso deve ceder à

120 tentação de embelezar literariamente a história" (HUIZINGA 2013, p. 102, tradução nossa). ${ }^{5}$

A maneira de Huizinga entender os documentos literários como expressões da historicidade da experiência humana e, portanto, auxiliares do historiador em suas pesquisas evidencia-se numa de suas obras mais importantes, $O$ outono da Idade Média (2010), na qual ele utiliza obras literárias, como as poesias de Deschamps, Meschinot, Chastellain, Chartier etc., para descrever as formas de vida e de pensamento dos séculos XIX e XV na França e nos Países Baixos.

\section{Um exemplo de conexão entre teoria literária e história da cultura: a contribuição metodológica de Alcir Pécora}

Na busca da apreensão do eixo unitário que perpassa os sermões de Antônio Vieira, Alcir Pécora (1994) encontrou um método de análise que se revela fecundo no que diz respeito à apreensão do conteúdo da fonte literária e não anacrônico do ponto de vista historiográfico. Pécora parte de uma crítica acerca de algumas análises e interpretações dos sermões vieirianos que observa terem sido construídas "sobre bases largamente anacrônicas, isto é, em torno de formulações que parecem incapazes de interrogar o seu objeto a partir [...] de

\footnotetext{
${ }^{2}$ No original: "genere letterario irrepreensibile".

${ }^{3}$ No original: "Attinge il suo materiale alla storia, dá um quadro di um determinato passato storico, ma come puro esercizio di belle lettere, senza pretendere che lo si consideri uma veritá rigorosa".

${ }^{4}$ No original: "ignorano quanto sia di buon gusto rinunziare a dire cose che non si conoscono".

${ }^{5}$ No original: "Lo storico deve resistere alla tentazione di abbellire leterariamente la storia".
} 
um tempo passado que seja mais do que pura arbitrariedade de sua enunciação" (PÉCORA 1994, p. 40). Isso produziria, entre outros resultados, uma anacrônica "estetização da experiência estética como esfera autônoma". Segundo o autor, é preciso "evitar a cada passo a tentadora substituição do enigma histórico pela originalidade anacrônica com que se o resolve" (PÉCORA 1994, p. 43, nota 14). Pécora propõe a "reposição do contexto histórico em que se inscreve e constitui a produção discursiva de Antônio Vieira" (PÉCORA 1994, p. 41), incluindo-se, por exemplo, "a concepção que preside o uso que faz da linguagem" (PÉCORA 1994, p. 41). Assim, é necessário entender "a maneira de ver" do autor "para se chegar a conhecer o significado do que diz" (PÉCORA 1994, p. 41). Nesse sentido, Pécora realiza a busca da "lógica de base" que perpassa a obra analisada inserindo-a numa "totalidade com a qual mantém uma relação essencial" (PÉCORA 1994, p. 42). Procura assim "levar a sério as formulações de base que articulavam as significações discursivas da época e, especialmente, as que forneciam a Antônio Vieira os lugares comuns de sua invenção" (PÉCORA 1994, p. 43). Em suma, "trata-se, em termos metodológicos da análise do discurso, de investigar os parâmetros de significação prévia presentes nas condições de produção dos sermões" (PÉCORA 1994, p. 44), ou seja, seguindo a indicação de Pêcheux, apreender o "conjunto das representações que delimitam as possibilidades de significação no interior de uma situação dada de interlocução" (PÉCORA 1994, p. 4, nota 16). Desse modo é possível, no conjunto da obra analisada, "detectar a recorrência complexa e sistemática de alguns de seus elementos essenciais em uma representação articulatória de base" (PÉCORA 1994, p. 67).

O método proposto por Pécora para a análise da obra sermonária de Antônio Vieira pode ser aplicado também ao estudo de fontes do mesmo gênero ou de gêneros próximos e constitui-se num interessante enfoque ao mesmo tempo histórico e teórico literário.

\section{Um exemplo do uso de fontes literárias na história dos saberes psicológicos: a novela do jesuíta Alexandre de Gusmão}

Na história dos saberes psicológicos, área de nossa atuação, é frequente o recurso às fontes literárias. No universo espaço-temporal da cultura brasileira colonial, por exemplo, destacamos as peças de oratória sagrada de Antônio Vieira, objeto de várias pesquisas voltadas para a apreensão dos saberes psicológicos (MASSIMI 2002a; 2005; 2009a; 2009b); bem como duas novelas alegóricas: uma de Alexandre de Gusmão, publicada em 1682 (MASSIMI 2012) e uma de Nuno Marques Pereira, publicada em 1728 (SILVA; MASSIMI 1997).

Os saberes psicológicos não dizem respeito apenas aos conteúdos das fontes mas também ao gênero em que elas se inscrevem: com efeito, seja no caso dos sermões como das novelas, a estrutura retórica de composição das fontes é construída de modo a produzir efeitos nos destinatários. Eles são obtidos pela mobilização do dinamismo psíquico realizada pela palavra (seja oral, seja escrita) ordenada, com os recursos de que a retórica dispõe (metáforas, evidência, composição de lugar, etc.). A definição dos efeitos desejados depende dos objetivos da obra. 
Tomemos aqui como exemplo a novela alegórica de Alexandre de Gusmão SI. A análise da obra foi desenvolvida por nós (MASSIMI 2012) utilizando o método de Alcir Pécora acima descrito, ou seja, buscando identificar a "lógica de base" de sua construção a partir da evidência das formulações discursivas presentes no texto e da apreensão de sua significação à luz do universo histórico-cultural em que a obra foi redigida. No âmbito do arcabouço conceitual que foi possível reconstituir a partir da identificação da lógica de base do texto e dos topoi nele recorrentes, buscamos apreender os saberes psicológicos, não baseados nas categorias da psicologia contemporânea (pois isso seria anacrônico), mas a partir das formulações discursivas presentes no texto e dos significados por elas assumidos, próprios do universo cultural do período histórico a que pertencem. Utilizando uma expressão de De Certeau, trata-se de identificar os saberes psicológicos no universo do pensável de um dado tempo histórico (CERTEAU 2000), ou seja, no campo das possibilidades conceituais disponíveis naquele momento.

Gusmão, educador jesuíta e diretor do Seminário de Belém em Cachoeira (Salvador), escreve este texto quase que paralelamente ao tratado pedagógico A arte de educar bem os filhos da idade da puerícia, publicado em Lisboa em 1685. A ênfase na relevância da atuação da Companhia de Jesus para o trabalho educativo da sociedade perpassa todo o tratado. Na novela, também, o papel da escola se revelará decisivo.

\section{Lógica de base, tópicos recorrentes e conceitos psicológicos na novela}

1220 motivo central da novela é a história de dois irmãos que, de modo diferente, vivenciam seus percursos existenciais, sendo esses percursos qualificados como peregrinações.

O tema da peregrinação possui significados conceituais que pertencem a um amplo domínio espaço-temporal. Trata-se de uma temática persistente na longa duração do tempo e em diferentes pontos do espaço geográfico, com conotações diversificadas e específicas em diversas épocas históricas e em diferentes tradições culturais, sociais e religiosas. No caso específico da novela de Gusmão, a peregrinação é tida como metáfora da vida humana entendida como percurso no tempo moldado por uma origem e uma direção a seguir em busca de um destino final. Nesse sentido, são propostos valores inerentes a essa orientação do tempo humano, assinalando-se condutas a serem encarnadas para que o destino possa ser alcançado com proveito. Evidenciam-se na leitura da novela dois valores fundamentais: a ação decisiva da liberdade como condição da ordenação da pessoa ao seu Destino; e a afirmação do papel da educação para a formação da pessoa.

Com efeito, o autor, ao construir a metáfora base do texto, é movido por uma intenção teológica e filosófica que é a de assinalar o papel decisivo do livrearbítrio no delineamento da história pessoal, acento propositalmente colocado com o objetivo de contrapor-se à leitura teológica do tema realizada pelo protestantismo e condensada na análoga obra $O$ peregrino: a viagem do cristão à cidade celestial, de 1678 (2004), de John Bunjam (1628-1680?). Além do mais, a imagem da peregrinação em Jerusalém é muito cara ao próprio fundador 
da Companhia, Inácio de Loyola (1991). Do objetivo visado por Gusmão de, por meio da novela, adentrar nesse debate teológico, são sinais os nomes dos dois protagonistas: Predestinado e Precito. A caracterização da diferença entre os dois irmãos, nascidos da mesma mãe e cuja origem assinala a condição universal do ser humano como peregrino, é dada, não somente pelo nome, mas pelo fato de que "Predestinado era casado com uma Santa e honesta virgem, chamada Razão. Precito era casado com uma ruim e corrupta fêmea, chamada Própria Vontade" (GUSMÃO 1685a, p. 7). Em suma, o eixo da personalidade de cada um é diferente: no primeiro caso, trata-se do uso da racionalidade; no segundo, é a afirmação da própria vontade.

O pleno entendimento do significado dessa diferença pode se obter lembrando o que Inácio de Loyola coloca em sua autobiografia, narrada em terceira pessoa; ao relatar os inícios de sua conversão, lembra que "notou [...] esta diferença: quando pensava nos assuntos do mundo, tinha muito prazer; mas quando depois de cansado, os deixava, achava-se seco e descontente". Pelo contrário, "quando pensava em ir a Jerusalém descalço [...], não se consolava só quando se detinha em tais pensamentos, mas ainda, depois de deixá-los, ficava contente e alegre". Essa experiência proporcionara a Inácio um maior conhecimento de si mesmo ("discernimento"): "colheu, então, por experiência, que de uns pensamentos ficava triste e, de outros, alegre. Assim veio pouco a pouco a conhecer a diversidade dos espíritos que o moviam" (LOYOLA 1991, p. 23). É justamente discutir essas diferenças nas figuras dos dois protagonistas o propósito da novela de Gusmão (MASSIMI 2012).

Apesar de tais diferenças, porém, Gusmão busca frisar que a condição humana é dotada das mesmas possibilidades: ambos os irmão preparam-se para o caminho de sorte, que costumam empreender os peregrinos, tendo os mesmos hábitos e dotados das mesmas potenciais virtudes (graça e proteção divina, fortaleza, constância, conforto espiritual, etc...), metaforizadas pelas roupas utilizadas (hábito, capa de pele de cordeiro, chapéu, bordão de peregrinos, alparcatas, alforje, cinta, bolsa). Assim Gusmão ressalta que o exercício da liberdade humana ocorre no impacto com a realidade, ou seja, diante das circunstâncias da vida (metaforizadas pela imagem da floresta e da mata) (MASSIMI 2012).

O outro valor destacado na novela é a importância da educação para a formação da pessoa. Sabemos que Alexandre de Gusmão foi fundador de um Colégio e autor de um tratado pedagógico. Já dissemos que, na novela, o papel da escola dos filhos é decisivo: a escola a ser escolhida pode ser a da verdade ou a da mentira. Conforme a opção feita, abre-se um diferente aprendizado: "eis que chegam das escolas os filhos de ambos referindo as lições, que naquele dia aprenderam. Os filhos de Predestinado referiam as excelências, que da santa Cidade de Jerusalém apregoavam os Profetas. [...]. Os filhos de Precito repetiam as grandezas, que de Babilônia referiam as escrituras" (GUSMÃO 1685 , p. 13). Assim, a escola proporciona o direcionamento de intenções e desejos de cada um em relação a um horizonte último, que é o próprio sentido da vida, metaforizado pelas duas cidades de Jerusalém e Babilônia. Ao longo da 
viagem, o discernimento acerca do melhor rumo depende da decisão acerca de uma meta reconhecida mais consoante ao desejo de felicidade e de realização que caracteriza o ser humano: ambos os peregrinos aspiram a ser felizes: tudo se joga na diferença que há entre amar a si mesmo como destino (destinado) e amar a si mesmo naquilo em que imediatamente nos espelhamos. Análogo é o percurso que ocorre nos Exercícios espirituais inacianos, onde, a partir da segunda semana, o sujeito é provocado a ler seu próprio desejo e nesse momento se faz presente a possibilidade do engano no discernimento (LOYOLA 1982). Ambos os protagonistas irão empreender um processo trabalhoso, mas cada um se posicionará conforme o que ama. Desse modo, Predestinado chega a Jerusalém por um caminho de purificação enquanto Precito chega a Babilônia e termina tragicamente sua jornada.

O que está em jogo é o destino da pessoa, tópico característico da tradição ocidental que sintetiza o dinamismo humano nas suas dimensões corporal, espiritual, psicológica, segundo as matrizes conceituais postas por Agostinho (1994), Aristóteles (2006) e Tomás de Aquino (2001). As três dimensões desse dinamismo compõem unitariamente a pessoa, mas possuem movimentos próprios (MASSIMI 2010a). O tema da pessoa e de sua educabilidade é central para Alexandre de Gusmão, conforme revela análise de suas outras obras. Com efeito, na Arte de criar bem os filhos na idade da puerícia (1685b), Gusmão compara os caracteres dos meninos aos metais das minas, os quais, mesmo tendo valor e consistência diferente, podem todos ser lavrados pela arte: "assim não há condição de menino tão ruim, que não possa ser domada pela boa educação". (GUSMÃO 1685b, p. 4). Em outra obra, Eleyçam entre o Bem e o Mal Eterno (1720), Gusmão recomenda o cuidado para com a alma por meio de seu conhecimento, pois "do conhecimento que tivermos das nossas almas depende o amor, que lhe devemos" (GUSMÃo 1720, p. 341). Neste contexto, pode-se entender que a História do Predestinado Peregrino e de seu irmão Precito (1685a) tem a função de evidenciar a importância desse cuidado de si e de propor alguns métodos para atuá-lo, assim como de descrever os efeitos nocivos do descuido: a pessoa realiza-se a si mesma somente na medida em que se desenvolve de modo ordenado conforme o seu destino último. Conhecimento da pessoa e prática de orientação da pessoa para que o seu ser em potência se atue coincidem na novela.

No que diz respeito aos saberes psicológicos, evidencia-se na novela um eixo importante e derivado da concepção antropológica dos jesuítas: para que o ser humano seja íntegro e realize seu destino, é preciso que a razão ordene o dinamismo pessoal; que a existência seja conforme à razão; e que a vontade seja submetida a uma alteridade e não se afirme por ela mesma. Há, com efeito, duas possibilidades inerentes ao ser humano e que colocam para ele constantemente uma escolha: ele pode viver conforme a razão ou conforme a própria vontade. Por sua vez, essas conformidades originam duas posições diferentes, metaforizadas pelos filhos dos dois casais: Predestinado tinha dois filhos de sua esposa Razão, Bom Desejo e Reta Intenção. Precito também tinha dois filhos de Própria Vontade: Mau Desejo e Torta Intenção (GUSMÃO 1685a, p. 
7). Em suma, o desejo ou apetite (afeto) e o movimento da vontade (intenção), podem ser orientados pela razão e, então, são bons e retos; ou pela vontade própria, sendo assim maus e tortos. E isso depende da educação na primeira infância, conforme assinala o autor: "sabia de quanto dano era criarem-se os filhos de sua primeira idade com Vontade Própria" (GUSMÃO 1685a, p. 8).

Na novela evidencia-se assim a concepção jesuítica acerca das interações entre dinamismo espiritual e dinamismo psíquico, ou seja, sobre o funcionamento das potências da alma, suas operações, suas doenças e seus remédios. Tais potências constituem-se na interface entre o corpo e o espírito. Com efeito, a ordenação da pessoa como um todo demanda um funcionamento saudável do dinamismo psíquico indicado pelo rótulo de "potências da alma". É a partir da ocorrência de alguma desordem nessas potências que se instalam as "más inclinações" nas pessoas. Na viagem dos dois peregrinos, as potências são metaforizadas pela imagem de um aparelho hidráulico composto por fontes de água (estas podendo, ou não, estarem limpas), canais e regatos. Segundo o relato, "estas fontes não são outras que as duas potências principais de nossa alma, Entendimento e Vontade, donde todo o bem e todo o mal provêm" (GUSMÃO 1685a, p. 260). As operações das duas potências principais ocorrem pela mediação de outras potências anímicas: as fontes correm por "dois canos que chamam Apetites Sensitivos", o cano Irascível e outro Concupiscível. Ambos os canos "se deságuam por onze regatos que chamam Paixões", isto é, os afetos. São eles: cinco paixões do Concupiscível (Amor, Ódio, Desejo, Abominação, Deleite, Gozo e Tristeza); e cinco paixões do Irascível (Esperança, Desesperação, Ousadia, Temor, Ira e Indignação) (GUSMÃO 1685a, p. 260).

Análoga concepção do psiquismo de matriz aristotélico-tomista pode ser encontrada nos tratados jesuítas rotulados de "Conimbricenses". Tais tratados, manuais escolares utilizados no Colégio das Artes de Coimbra, constituem-se nos alicerces fundamentais da formação dos jesuítas em Portugal e em suas colônias. O nome "Conimbricenses" deriva do fato de terem sido redigidos pelos professores do referido Colégio. Tais manuais foram utilizados para os estudos filosóficos nos colégios da Companhia no Brasil (GIARD 1995; MASSIMI 2002a). Trata-se de comentários dos textos gregos de Aristóteles. No caso do estudo antropológico e psicológico, destacam-se os seguintes textos: o comentário ao tratado De Anima (Sobre a alma; GÓIS 1602), o comentário ao tratado Parva Naturalia (Pequenas coisas naturais; GóIS 1593a), o comentário ao tratado Ética a Nicomaco (GÓIS 1593b), o comentário ao De Generatione et Corruptione (Sobre a geração e a corrupção; GÓIS 1607).

Há também uma profunda analogia de visão entre tais tratados e a novela de Gusmão no que diz respeito à concepção do nexo entre apetites e valores espirituais. Quanto ao apetite intelectivo ou vontade, nos tratados Conimbricenses, sobretudo na Primeira disputa da ética, escrita por Góis em 1593 (1957), afirma-se que o ato de apetecer evidencia a inclinação de todas as coisas para o bem. Todavia, no caso dos seres humanos, esse bem pode ser por eles identificado com um objeto não apropriado à reta razão e à lei divina. Assim, quando ao bem natural se opõe um bem maior, o homem deve ser 
capaz de discernir e optar por ele. Disso decorre que o sujeito que faz o mal, não quer o mal como tal, mas "enquanto aparece bem", orientado por "alguma imagem imperfeita de bem" (GÓIS 1957, p. 83). Gusmão parece aderir a essa posição ao apresentar o dinamismo de Precito: a causa de seus desvios não é o exercício da vontade por si mesma, mas o fato de ela ser mal direcionada, por não estar submetida à razão. De certo modo, a vontade de Precito regredira ao nível das paixões, dos apetites sensitivos. Por isso, para o bem viver, torna-se decisivo o trabalho do cultivo dos apetites e das demais potências, bem como a identificação das "enfermidades" da alma, cujo desenvolvimento é descrito em pormenores por Gusmão. Ele retrata o adoecimento anímico, em analogia com as doenças do corpo, como uma "infecção" decorrente do fato de que nas águas das fontes (potências) se infiltram as "más inclinações" (MASSIMI 2012).

No que diz respeito à concepção do nexo entre apetites sensitivos (afetos) e valores espirituais, encontra-se também convergência entre a visão dos Conimbricenses e a novela de Gusmão: os afetos são inclinações do apetite sensitivo que movem a vontade. Todavia, em conformidade com a teoria aristotélica, "o apetite não move a vontade imperando-Ihe" (GÓIS 1957, p. 159), mas por "por intermédio da notícia intelectiva" do objeto, já que, por tratar-se de uma faculdade psíquica inferior, ligada ao órgão corporal, que é material, como tal não pode obter o domínio sobre uma potência superior e imaterial. Se, porém, a vontade for arrastada pelo apetite de modo tal que não tenha poder para lhe resistir (quando esse apetite "for tão veemente que 126 absorva absolutamente o uso da razão"), o afeto tornar-se-á uma inclinação intensa e desordenada que "perturba [...] e absorve o juízo". Eis aqui explicado pelos filósofos de Coimbra o processo vivenciado por Precito na novela: levado para Samaria por Engano, seu conselheiro, primeiro ele se hospeda na "casa da Vaidade" e, depois, por estímulo dos seus dois filhos Mau desejo e Torta Intenção, resolve seguir o caminho da Vaidade e adentra numa terra regida pelo velho "Vício", onde dissipa sua vida governado pela "concupiscência da carne, concupiscência dos olhos, soberba" (GUSMÃO 1685a, p. 247). Da união com a esposa Própria Vontade, Precito gera outros dois filhos Desprezo às coisas eternas e Estimação das coisas temporais. Como consequência dos rumos escolhidos por Precito, ocorre um desequilíbrio interior das potências psíquicas, "de tal sorte que não parecia homem de razão" (GUSMÃo 1685a, p. 247). Resulta, no fim, a "confusão" que o atormenta "com mil tristezas, desgostos e inquietações" e uma "serpente de terrível aspecto" metáfora da "própria Consciência".

Em suma, Precito é o caso exemplar do desvio da vontade em relação ao seu alvo, desvio esse que acarreta a desordem dos atos humanos. A desordem da experiência humana assim configurada é a "doença" que a formação jesuítica proposta por Inácio e por seus seguidores busca "remediar" por meio de um trabalho sistemático de ordenação das dimensões pessoais. Não se trata de neutralizar ou desconsiderar a ação das potências psíquicas, já que elas são elementos constitutivos da experiência humana, mas cabe aprender a lidar com esses fenômenos de modo a torná-los fatores construtivos do desenvolvimento da pessoa para que ela possa atingir "a moderação e o equilíbrio" (GÓIS 1957, p. 199). 
O caminho do Predestinado é exemplar desse processo: os remédios a ele propostos ao longo da jornada correspondem aos grandes pilares da pedagogia jesuítica; trata-se do bom uso da razão, orientada em sua busca da verdade e do bem pela moralidade (reta intenção e bom desejo). Esta, por sua vez, saberá ordenar bem vontade e afetos. Ao Predestinado é aconselhado entregarse ao "cuidado da esposa Razão e dos dois filhos Bom desejo e Reta intenção" (GUSMÃO 1685a, p. 261). Um alimpará o entendimento, outra "terá cuidado de ordenar bem a vontade" (GUSMÃO 1685a, p. 261). Na tradição jesuítica e, de modo geral, no cristianismo da Idade Moderna, esse exercício interior é chamado de "desengano".

Na novela, o Desengano é uma personagem que aconselha Predestinado e é caracterizado como aquele que "fixa os olhos em Verdade". Junto aos conselhos de Desengano, o peregrino recebe por um anjo uma tocha, feita de cera muito pura, "fabricada por umas abelhas, que chamam Potências da alma" com o pólen de "flores trasladadas do Paraíso ao jardim da Igreja Católica" e que metaforizam a Graça divina (GUSMÃO 1685a, p. 261). Isso significa que o desengano é proporcionado, por um lado, pelo dinamismo anímico (as abelhas, a saber, as potências da alma, que têm um papel ativo no processo) e, por outro, por algo dado (as "flores" provenientes do Paraíso, ou seja, a Graça). Aqui transparece a posição teológica dos jesuítas acerca da relação entre liberdade humana e iniciativa divina, relação essa questionada pela doutrina do protestantismo que reafirma com força a predominância da Graça (BUZZI 2000).

A crença na função decisiva das potências da alma no percurso do desengano demanda o conhecimento de sua atuação, e isso justifica a atenção reservada à dimensão psicológica na antropologia jesuítica. A articulação entre as potências anímicas no exercício do desengano é ilustrada por Gusmão ao retratar o "Palácio do Desengano". Em primeiro lugar, destaca-se a memória: todos os acessos ao Palácio correspondem a atividades da memória aplicada a objetos específicos (eternidade, morte, juízo, interno, paraíso, lembranças do passado presente e futuro). Outra potência anímica envolvida no processo é o entendimento: o trono do Desengano no Palácio é a esfera do mundo girando por volta de dois polos, a vida e a morte, num movimento constante entre eles; a tomada de consciência da mutabilidade da condição humana consiste na apreensão desse movimento constante de alternância entre dimensões opostas da realidade. Os atos da memória e do entendimento são eficazes desde que sejam acompanhados pelo uso correto dos sentidos, que, por sua vez, depende da decisão da vontade. Esta é exercitada por meio de três práticas, que são a Lição, a Oração e a Meditação, exercícios expressivos do carisma jesuítico. Gusmão descreve em pormenores cada uma das três práticas e os recursos a elas inerentes, representando-os sempre por meio de metáforas topológicas e de personagens alegóricas. Destaque especial é dado ao bom uso dos sentidos internos (memória, imaginação, senso comum e vis cogitativa), proporcionado pelo método inaciano da Compositio Loci, que Gusmão retrata em detalhes (LOYOLA 1982). Tal método consiste em representar-se na imaginação o mistério a ser meditado, colocando-se mentalmente no lugar onde o fato aconteceu. $\mathrm{Na}$ 
novela, o uso desse método é descrito quando Predestinado, entrando numa sala do Palácio de Desengano chamada de Composição de Lugar, recebe um quadro pintado representando uma cena evangélica e oferece-o para três virgens chamadas Memória, Inteligência e Vontade (GUSMÃO 1685a, p. 80).

A ordenação dos afetos (apetites sensitivos) e da vontade (apetite intelectivo) abre o acesso à virtude central para os jesuítas, a obediência. Conforme a visão inaciana, a obediência encontra fundamento na filosofia humana (aristotélica) e confirmação no preceito divino, sendo a virtude fundamental para ordenar a vida espiritual, social e política. Na novela, Gusmão apresenta, em pormenores, outras práticas da tradição jesuítica, úteis para a ordenação da pessoa e especialmente para adquirir a virtude da obediência: o exame de consciência e o recurso à direção espiritual (metaforizada pela figura do médico espiritual).

O último tópico importante no que diz respeito à visão antropológica e psicológica presente na novela de Gusmão é o do coração: ao retratar a longa jornada de Predestinado e de Precito, Gusmão disserta sobre o coração humano e sua identificação com o coração divino. Segundo o autor, essa união ocorre numa das etapas finais da caminhada, como resultado do processo de aperfeiçoamento do ser humano em vista de seu Destino e em coincidência com a representação da via dolorosa transitada por Cristo a caminho do Monte Calvário. Essa via, marcada por sete passos, é percorrida por Predestinado em companhia de figuras alegóricas representando as virtudes, e, a cada passo, seu coração sofre uma transformação decorrente da contemplação da representação

128 do Cristo sofredor. Ao termo do percurso, tais figuras, "estendendo o coração do Peregrino fortemente na própria Cruz do Senhor, o pregaram nela com os próprios cravos com que o mesmo Cristo estava crucificado" (GUSMÃO 1685a, p. 237). O topos da impressão, a estampa no coração, remete a outro mais antigo, o da escritura no coração (BOLZONI 2010). O tema do retrato da pessoa amada pintado ou esculpido no coração é presente na tradição lírica ocidental desde a Idade Média. Segundo Bolzoni, não se constitui apenas uma metáfora linguística, mas adquire também consistência material; não se trata de simples analogia, mas de um trânsito entre o espírito e a carne, entre a palavra e o corpo. O coração, lugar da interioridade, possui também evidência exterior: pode-se dizer que é o lugar de trânsito entre interioridade e exterioridade (BOLZONI 2010). Ainda segundo essa autora, tal concepção deve ser entendida a partir de uma tradição muito antiga que atribui dimensão espacial às potências anímicas como, por exemplo, a memória. O coração torna-se o repositório das imagens da memória, de modo que se diz que a imagem do objeto amado se imprime no coração (BOLZONI 2010; CARRUTHERS 2006).

Em suma, podemos identificar os topoi principais da novela, suas matrizes conceituais e o conjunto de saberes psicológicos que ela elabora e transmite.

\section{Recursos retóricos e efeitos psicológicos na construção da novela}

Os saberes psicológicos são propostos na novela mediante recursos literários como alegoria e metáfora. Sabe-se que a utilização de imagens do mundo da natureza para metaforizar situações morais, interiores, ou referentes ao sagrado 
é comum no período da Idade Moderna e na tradição jesuítica (MASSIMI 2007; 2008). O amplo uso de tais recursos pode ser explicado em função das finalidades pedagógicas da novela. Em sua composição, Gusmão inspira-se em gêneros literários análogos e utiliza-se de conhecimentos de retórica e especialmente de retórica jesuítica (como, por exemplo, a composição de lugar, o uso de metáforas e alegorias). Na perspectiva da história dos saberes psicológicos, buscamos compreender, pela análise da novela, o efeito da narrativa alegórica no dinamismo psíquico dos destinatários, efeito visado pelo autor mediante o uso de recursos próprios do gênero literário.

A palavra retoricamente ordenada, a construção da metáfora base (a partir da qual se desenvolve o enredo da novela) e a disposição das alegorias são todos elementos que agem com eficácia no dinamismo psíquico dos destinatários, realizando os objetivos pretendidos, a saber: deleitar, mover, ensinar. Tais efeitos são obtidos pela mobilização das potências anímicas: os sentidos (externos e internos) evocam afetos e provocam as operações do entendimento e da vontade (MASSIMI 2005; 2008b; 2009a). Focamos o funcionamento desses aspectos na novela de Gusmão.

Em primeiro lugar, a palavra pode ser disposta segundo os ditames da arte retórica na transmissão oral (pregação) e na transmissão escrita (novela). Em ambos os casos, a dinâmica de ação da palavra retoricamente ordenada assemelha-se. Além do mais, possivelmente, a novela foi construída para ser não apenas lida como também ouvida, tendo por destinatários não apenas leitores como também ouvintes; devendo, portanto, suscitar efeitos similares aos proporcionados por um sermão devido à composição ordenada de palavras e imagens segundo os ditames da arte retórica. A eficácia de sua ação junto aos destinatários é determinada pela mobilização articulada das potências do dinamismo psíquico, que, por sua vez, permite o processo de conhecimento visando à transmissão de determinados valores.

Em segundo lugar, deve ser destacada a função da metáfora base do texto, a da peregrinação. Na peregrinação dos protagonistas da novela, o itinerário, os lugares e as imagens encontradas pelos transeuntes adquirem um significado alegórico. Santos (2004) frisa a importância da metáfora da peregrinação no horizonte da tradição ibero-lusitana, comentando que nas primeiras décadas do século XVII, em Portugal, na literatura do movimento da Arcádia, o tema da peregrinação era recorrente: "a viagem, $[\ldots]$ contribuía para a organização deste modelo narrativo" (SANTOS 2004, p. 588). O mesmo ocorre "com o uso da alegoria ou de processos alegóricos, nas variadíssimas tipologias discursivas que, prolongando filões que a Idade Média tinha desenvolvido, atravessaram os séculos XVI e XVII". Segundo a mesma autora, a essa tradição se remeteria inclusive Inácio de Loyola: "a provável matriz alegórica dos Exercícios Espirituais teria "como marca impressiva" a "leitura de El Pelegrino de la vida humana (Toulouse, 1490) por Inácio de Loyola" (SANTOS 2004, p. 588).

Em terceiro lugar, vejamos os demais dispositivos retóricos utilizados pelo autor: as imagens linguísticas em forma de emblemas, empresas e alegorias. Na Idade Moderna, as imagens (pinturas, estátuas, emblemas, 
empresas, metáforas e alegorias...), além de serem empregadas nas práticas culturais e religiosas tendo em vista sua eficácia em comunicar conceitos, agem como dispositivos retóricos que provocam nos destinatários diversos modos de elaboração. A eficácia dessa elaboração, por sua vez, depende da ativação das potências psíquicas, especialmente da atividade sensitivo-imaginativa (sentidos internos), ordenada para alcançar o fim último. A retórica da Idade Moderna sugere o uso dos emblemas e das empresas, dois gêneros alegóricos que contêm ora a imagem ora o texto escrito. Gusmão (1685, p. 135) faz uma referência explícita no texto da novela à arte da emblemática de Alciati e, sobretudo, conforme ressaltado por Santos (2004, p. 592), utiliza-se na construção da obra do "conjunto de saberes tributários da emblemática". Desse modo, "o fundamental caráter alegórico" da obra "Ihe advém do persistente recurso à explicação pormenorizada de pequenos quadros, formados, sobretudo, por 'figuras'" com base nos "conhecimentos em áreas dependentes do complexo e afortunado filão constituído por emblemas, hieróglifos e empresas". E, como ainda evidencia Santos, "tal opção não se reveste de qualquer singularidade, se enquadrada no apreço que a Companhia votou à Emblemática e no peso e importância que os jesuítas concederam aos 'libri figurati'" (SANTOS 2004, p. 592).

A imagem é utilizada como emblema e empresa quando representa objetos ilustrativos de um conceito, sendo acompanhada por uma escrita explicativa. No caso do emblema, a escrita chama-se "lema"; no caso da empresa, o escrito chama-se "termo". Por emblema entende-se um símbolo, composto por figura e palavras, a ser usado como decoração de salas, de aparatos, ou nos livros de imagens e explicações destinados ao ensino. A empresa originariamente era uma figura simbólica que ornava as vestes ou as armas dos cavaleiros, acompanhada por uma frase alegórica; a partir do século XVI, configura-se como representação simbólica de um propósito ou de uma linha de conduta por meio de uma palavra e de uma figura que se interpretam uma à outra. Por fim, o epigrama apresenta um conceito (referente ao lema ou termo) que ilustra os objetos representados. A suma dessas imagens alegóricas encontra-se numa obra muito especial, a obra acima citada de Andrea Alciati (1492-1550), Emblemata (1531) - protótipo absoluto dessas produções.

Na tradição cultural dos jesuítas, o uso de emblemas e empresas é decorrente de duas características espirituais e pedagógicas do carisma inaciano. Em primeiro lugar, a imagem veicula a mensagem sagrada, como o próprio Inácio frisa nos Exercícios. Em segundo lugar, Inácio considera a imagem como eficaz do ponto de vista de sua ação na subjetividade da pessoa, especialmente na memória e na imaginação, de modo a facilitar a meditação e, como vimos, nessa perspectiva define o método da compositio loci. Seguindo tal orientação, no final do século XVI, o jesuíta Jerônimo Nadal realiza o projeto de construção de um método ótico e intuitivo de oração com a publicação do livro Adnotationes et meditationes in Evangelia quae in sacrosancto missae sacrificio toto anno leguntur cum eurundem Evangeliorum Concordantia (Antuerpia, Moretum, 1593) (INSOLERA 2004). 
No ensino dos Colégios da Companhia, utilizam-se também esses recursos numa ótica mais propriamente cultural e menos espiritual, na perspectiva do saber humanista, literário, filosófico: a composição dos emblemas torna-se assim um dos exercícios didáticos propostos aos estudantes. Na edição de 1591 da Ratio Studiorum, as regras para os professores de retórica e de humanidades sugerem que os alunos sejam ensinados a fazer desenhos para ilustrar os emblemas. Além do uso das imagens voltado para a direção espiritual, vários jesuítas professores de retórica e de humanidades nos colégios publicam textos de emblemas, seguindo a tradição clássica, mas com matriz cristã, operando assim uma sorte de cristianização da tradição da emblemática clássica (INSOLERA 2004).

$\mathrm{Na}$ perspectiva dos jesuítas, a função pedagógica dos emblemas era a de materializar o sobrenatural de modo a torná-lo compreensível para todos (INSOLERA 2004, p. 52). Em conformidade com essa tradição de pertença, Alexandre de Gusmão parece ter construído a novela visando, pela mobilização articulada das potências do dinamismo psíquico, promover um processo de conhecimento voltado à transmissão dos valores e conteúdos que acima assinalamos. De modo especial, o uso da emblemática e de saberes afins envolve a mobilização da potência anímica da memória com objetivo pedagógico e persuasivo: trata-se do uso de "estratégias propiciadoras da 'memória', como formas privilegiadas da persuasão". De fato, "as entidades alegóricas cumprem a sua função de 'auxiliares' da memória, preenchendo uma relevante dimensão pedagógica" (SANTOS 2004, p. 595).

Em suma, o objetivo pedagógico a ser alcançado na composição da "peregrinação" narrativa de Gusmão realiza-se por meio de recursos da retórica que promovem a articulação da memória com a imaginação, a sensibilidade, o afeto, o pensamento e a decisão. Para o entendimento da construção do arcabouço do texto, arcabouço ao mesmo tempo conceitual e retórico, revelou-se essencial o uso de uma abordagem que combinasse a história dos saberes psicológicos com a história dos gêneros retóricos e da literatura.

\section{Conclusão}

A análise do texto de Gusmão foi possível pela intersecção das perspectivas literária, histórica e psicológica. Por meio do emprego do método de análise sugerido por Pécora, pudemos identificar os topoi presentes na novela e as articulações pelas quais o autor construiu o texto. Ao buscar entender os efeitos comunicativos pretendidos pela novela, detivemo-nos na construção do arcabouço retórico da obra, especialmente no emprego dos recursos da arte retórica como alegorias, metáforas e emblemas e em certo uso da palavra retoricamente ordenada visando o efeito de transmitir conhecimentos e de promover, pela persuasão, mudanças de conduta. A fonte é expressiva, portanto, de um universo multifacetado que, por sua natureza, exige abordagem multidisciplinar por se situar num tempo histórico em que não há solução de continuidade entre o âmbito teológico, filosófico, retórico e psicológico. Desse modo, foi possível apreender aquela "conexão viva da experiência" a que se referia Dilthey, na qual as diversas dimensões (histórica, psicológica, antropológica, cultural, etc.) se 
apresentam de forma unitária. O exemplo proposto evidenciou que a literatura como "forma cultural" (empregando a expressão de Huizinga acima citada) pode ser utilizada para descrever as modalidades de vida e de pensamento próprias de um dado tempo histórico.

\section{Referências bibliográficas}

AgOStinho DE HIPONA. A Trindade. Traduzido por A. Belmonte. São Paulo: Paulus, 1994 [414].

ALCIATI, Andrea. Emblemata. Paris: Edições Steyner, 1531.

AMARAL, Maria N. C. P. Dilthey: um conceito de vida e uma pedagogia. São Paulo: EDUSP/Perspectiva, 1987.

BARIANI, Edison. D. Dominick LaCapra: tecendo textos e contextos. Revista Espaço Academico, n. 61, 2006. Disponível em: http://www.espacoacademico. com.br/061/61bariani.htm\#_ftn4. Acesso em: 4 jun. 2014.

BOLZONI, Lina. Il cuore di cristallo. Torino: Einaudi, 2010.

BUNJAM, John. O peregrino: a viagem do cristão à cidade celestial. Traduzido por A.H. Silva. São Paulo: Editora Martin Claret, 2004 [1678].

BUZZI, Franco. Teologia e cultura cristiana tra XV e XVI secolo. Genova: Marietti, 2000.

132 CARRUTHERS, Mary. Machina memorialis: meditazione, retorica e costruzione delle immagini (400-1200). Traduzido por L. Iseppi. Pisa: Edizioni della Normale, 2006 [1998].

CERTEAU, Michel de. A escrita da história. Traduzido por M. L. Menezes. São Paulo: Editora Forense, 2000 [1975].

CHARTIER, Roger. A história cultural entre práticas e representações. Traduzido por Manuela Galhardo. Lisboa: editora Difel, 1990.

DILTHEY, Wilhem. Ideen über eine beschreibende und zergliedernde Psychologie. Sitzungs- berichte Akademit der Wissenschaíten 2. Berlin, 1894.

A construção do mundo histórico nas ciências humanas. São Paulo: Editora da Unesp, 2006 [1970].

DOSSE, François. História e ciências sociais. Baurú: Editora Edusc, 2004.

GIARD, Luce. Les jésuites á la Renaissance: système éducatif et production du savoir. Paris: PUF/ Bibliothèque d'histoire des sciences, 1995.

GÓIS, Manuel. Commentarii Collegii Conimbricensis Societatis Iesu. In:

Libros Aristotelis qui Parva Naturalia appellantur. Lisboa: Simão Lopes, 1593a.

. Commentarii Collegii Conimbricensis Societati Iesu. In: .Tres

libros de anima. Veneza : Tipografia Vincenzo Amadino, 1602. 
. Commentarii collegii conimbricensis Societatis Iesu. In: Libro de generatione et corruptione Aristotelis Stagiritae nunc recens omni diligentia recogniti et emendati. Veneza: Tipografia Vincenzo Amadino, 1607.

Disputas do curso sobre os livros da moral da ética a Nicomaco, de Aristóteles em que se contêm alguns dos principais capítulos da Moral. Traduzido por A.B. Andrade. Lisboa: Instituto de Alta Cultura, 1957 [1593].

GUSMÃO, Alexandre. SI. A arte de criar bem os filhos da idade da puerícia. Lisboa: Deslandes, 1685.

- História do Predestinado Peregrino e de seu Irmão Precito. Lisboa: Deslandes, 1685 [1682].

. Eleyçam entre o bem e o mal eterno. Lisboa: Oficina Da Musica, 1720.

HUIZINGA, Joannes. La scienza storica. Il suo valore, la sua attualità. Traduzido e organizado por Ovidio Capitani. Milano: Editora Res Gestae, 2013 [1934].

INSOLERA, Luisa. S. L'imago primi saeculi (1640) e il significato dell'immagine allegorica nella Compagnia di Gesú. Genesi e fortuna del libro. Roma: Editrice Pontificia Universitá Gregoriana, 2004. (Miscellaneae Historiae Pontificiae v. 66)

LACAPRA, Dominick. Rethinking intellectual history; texts, contexts, language. $2^{\text {nd }}$ ed. Ithaca: Cornell University Press, 1985a.

. History and criticism. Ithaca: Cornell University Press, 1985b.

History and criticism. $3^{d}$ ed. Ithaca; London: Cornell University Press, 1992.

History in Transit: Experience, Identity, Critical Theory. Ithaca: Cornell UP, 2004.

LOYOLA, Inácio. Obras completas, n. 86. Madrid: Bibliotecas Autores Cristianos, 1982.

Autobiografia. Traduzido por A. Cardoso. São Paulo: Edições Loyola, 1991 [1555].

. Cartas. Traduzido por A. Cardoso. São Paulo: Edições Loyola, 1993.

MASSIMI, Marina. A Psicologia dos jesuítas: uma contribuição à História das Idéias Psicológicas. Psicologia. Reflexão e Crítica, v. 14, p. 625-633, $2002 a$.

. Palavras, almas e corpos no Brasil colonial. São Paulo: Edições Loyola, 2005b, p. 330. v. 1.

- Imagens da natureza na pregação jesuítica em Terra Brasilis In: 
BAPTISTA, Ana Maria Haddad. (org,) A natureza nos Novos Mundos. $1^{\text {a }}$ ed. Lisboa: Apenas, 2007, p. 28-47. v. 1.

. Imagens da natureza e afetos humanos em sermões brasileiros dos séculos XVII e XVIII In: Haddad, A. Imagens da Natureza. Lisboa: Apenas, 2008.

. Deletare, movere et docere: retórica e educação no Barroco. Per Musi, UFMG, v. 17, p. 54-59, 2008b.

- Estudos sobre a contribuição da antiga Companhia de Jesus ao desenvolvimento dos saberes sobre o psiquismo. CLIO. Série História do Nordeste, UFPE, v. 2, p. 163-191, 2009a.

. Imagens, dinamismo sensorial e elaborações retóricas no Brasil colonial. Interamerican Journal of Psychology, v. 43, p. 374-382, 2009b.

. A pessoa e o seu conhecimento: algumas etapas significativas de um percurso. Memorandum, Belo Horizonte, v. 18, p. 10-26, 2010 a.

. A novela História do Predestinado Peregrino e de seu irmão Precito (1682). Compêndio de saberes antropológicos e psicológicos dos jesuítas no Brasil colonial. São Paulo: Editora Loyola, 2012.

PÉCORA, Alcir. Teatro do sacramento. São Paulo: Editora Edusp/Editora Unicamp, 1994.

134 PINTO, Aline Magalhães; VALINHAS, Manuella Luz de Oliveira. Historicidade, retórica e ficção: interlocuções com a historiografia de Dominick La Capra. Revista Rhêtorikê, n. 3, p. 1-18, 2010.

SANTOS, Zulmira. Emblemática, memória e esquecimento: a geografia da salvação e da condenação nos caminhos do "prodesse ac delectare" na História do Predestinado Peregrino e seu Irmão Precito (1682) de Alexandre de Gusmão S] [1629-1724]. Porto: Universidade do Porto, 2004.

SILVA, Paulo José Carvalho; MASSIMI, Marina. A construção do conhecimento psicológico na obra História do predestinado peregrino e seu irmão Precito (1682) de Alexandre de Gusmão S. J. [1629-1724] Revista da Sociedade Brasileira de História da Ciência, 17, p. 71-80, 1997.

TOMÁS de Aquino. Suma Teológica. Traduzido por C. P. de Oliveira. São Paulo: Edições Loyola, 2001 [1273]. 